\title{
¿Es la destrucción del patrimonio un crimen de guerra?
}

Jaime Vergara-Muñoz, Miguel Martínez-Monedero | Universidad de Granada

URL de la contribución <www.iaph.es/revistaph/index.php/revistaph/article/view/4091>

La destrucción voluntaria e innecesaria de los bienes culturales durante un conflicto armado es una violación de la Convención de 1954, y por lo tanto un crimen de guerra dentro de las competencias del Tribunal Penal Internacional para procesar.

Recientemente hemos vivido un ejemplo. El juicio de Ahmad al-Faqi al-Mahdi. Un islamista que reconoció en 2016 ante el Tribunal Penal Internacional haber incentivado en 2012 el destrozo de joyas religiosas y arquitectónicas en la ciudad santa de Tombuctú ${ }^{1}$, al norte de Malí. La ONU lo llamó un "crimen contra la historia".

Mahdi era jefe de la Hesba ${ }^{2}$, una de las cuatro estructuras administrativas del grupo Ansar Din, asociado con Al Qaeda del Magreb Islámico (AQMI), que había ocupado el norte de Malí en 2012 y había establecido su cuartel general en Tombuctú en abril, después de expulsar a los combatientes del Movimiento de Liberación del Azawad (MNLA). Se le acusaba de un crimen de guerra cometido al dirigir intencionalmente ataques contra monumentos históricos o edificios dedicados a la religión durante los meses de junio y julio de 2012. Se declaró culpable de los cargos de la destrucción de nueve mausoleos y una mezquita ${ }^{3}$. Durante el juicio se reconoció arrepentido e imploró el perdón y las disculpas de los habitantes de la ciudad y de la comunidad internacional por el daño a la herencia del país africano y de toda la humanidad.

El juicio contra el yihadista es singular ${ }^{4}$. Esta es la primera vez que la Corte Penal Internacional (CPI) recibe una denuncia -en este caso del Estado maliense- relacionada con la destrucción de monumentos culturales y que califica estos actos como crímenes de guerra. Nunca antes se había juzgado específicamente por cometer crímenes contra el patrimonio, a pesar de que la destrucción de monumentos ha sido por desgracia una constante en los conflictos bélicos.
Detenido en 2015, Al Mahdi fue condenado por la CPI el 27 de septiembre de 2016 a nueve años de prisión y el 17 de agosto de 2017 a pagar 2,7 millones de euros a las víctimas en concepto de reparación ${ }^{5}$. Si bien es cierto que, hasta ahora en las guerras, el objetivo central de los atacantes no había sido el patrimonio construido, en el nuevo terrorismo es justo lo contrario. Intentan barrer al enemigo no solo físicamente, sino a través de todo aquello que representa su cultura.

Ciudades como Palmira (Siria) o Nimrod (Iraq) han sufrido en su patrimonio cultural la dureza del "genocidio cultural"6 que los fundamentalistas necesitan para implantar su doctrina. En otro orden, también en Iraq en 2003, soldados de EE.UU. realizaron pintadas y robaron ladrillos milenarios de la ciudad sumeria de Ur con un sentido de la propiedad que no les correspondía.

En casos como el de Tombuctú, la condena queda incompleta en cuanto a la restitución del patrimonio, aunque se trata de un hito porque reconoce la importancia de la herencia cultural, no sólo en las comunidades directamente afectadas, sino en la humanidad. Es de común acuerdo que la destrucción del patrimonio no sólo daña monumentos arquitectónicos, sino que arrasa con el tejido social, cultural e histórico de las comunidades.

El juicio contra Madhi tuvo bastante revuelo mediático. Muchos argumentaban que la destrucción del arte es sin duda un delito, pero no se puede comparar al asesinato de seres humanos para juzgarlo con la CPI.

En nuestra opinión está claro que existen distinciones legales entre el asesinato de seres humanos y la destrucción cultural aunque, en realidad, los dos están a menudo conectados. En el caso de Madhi, por ejemplo, al declararse culpable de los crímenes de guerra, lo hace de un delito que incluye, de facto, tanto la muerte 
_a debate Patrimonio, terrorismo y desastres naturales ¿Cómo prevenir y abordar los enormes daños al patrimonio cultural mundial?

| coordinan Francisco Javier López Morales, Francisco Vidargas

de civiles como la destrucción de los bienes artísticos. Por eso cada una de estas acciones es juzgada en virtud de tratados diferentes. La segunda por la Convención de La Haya ${ }^{7}$ de 1954 para la protección de la propiedad cultural en caso de conflictos armados, y aún queda la sentencia de la primera cuya investigación es más amplia y aún está en curso ${ }^{8}$.

La destrucción del patrimonio cultural nos posiciona ante una evidencia de crímenes contra la humanidad, ya que el desarrollo social -o el simple progreso- de una civilización se frena o se extingue si las raíces culturales son atacadas. Ante estos acontecimientos, el apoyo de la comunidad internacional es fundamental para prevenir situaciones de este tipo. El apoyo legal y las sentencias no son reparadoras, pero sí hacen justicia a delitos que antes quedaban impunes y crean jurisprudencia.

Vivimos en una sociedad afectada por el conflicto, y el patrimonio cultural puede ayudar a la reconciliación. La conservación, por parte de todos, del patrimonio heredado es una garantía de progreso y convivencia pacífica.

La acusación de Mahdi es una novedad en la historia de la CPI, y una evidencia de que, 71 años después de los juicios de Nuremberg, la comunidad internacional sigue luchando para procesar a los que atacan la cultura y, por tanto, a las personas.

\section{NOTAS}

1. Tombuctú, también conocida como "la ciudad de los 333 santos", alberga gran cantidad de tumbas, mausoleos y morabitos. Este tipo de culto ha sido rechazado por algunos islámicos más radicales que se oponen a cualquier culto que no sea el más más estricto monoteísmo.

\section{Una especie de "policía moral" islamista.}

3. Mausoleo de Sidi Mahmoud Ben Omar Mohamed
Aquit, el de Sheikh Mohamed Mahmoud al-Arawani, de Sheikh Sidi el-Mokhtar Ben Sidi Muhammad Ben Sheikh Alkabir, de Alfa Moya, de Sidi Mahmoud Ben Amar, de Sheikh Muhammad El Micky, de Cheick Abdoul Kassim Attouaty, de Ahamed Fulane, y el de Bahaber Babadié, además de la Mezquita Sidi Yahya.

4. Se puede consultar una entrevista realizada por Anissa Barrak en <https://es.unesco.org/courier/2017-octubre-diciembre/ahmad-al-faqi-al-mahdi-me-declaro-culpable> [Consulta: 06/12/2017]

5. Más detalle en la web de International Criminal Court y Trial Internacional.

6. En palabras de la secretaria general de la UNESCO, Irina Bokova.

7. Se puede consultar el contenido de la Convención en la web UNESCO <http://portal.unesco.org/en/ev.php-

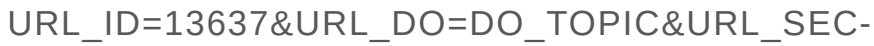
TION=201.html> [Consulta: 06/12/2017]

8. La causa por atentado contra el legado artístico no anula que se abra al acusado otro proceso por crímenes de otro tipo.

\section{BIBLIOGRAFÍA}

- INTERNATIONAL CRIMINAL COURT (22/08/2016) Declaración del Fiscal de la Corte Penal Internacional, Fatou Bensouda, en la apertura del juicio en el caso contra Ahmad Al-Faqi Al Mahdi <https://www.icc-cpi.int/Pages/item. aspx?name=otp-stat-al-mahdi-160822 $\geq$ [Consulta: 06/12/2017]

- INTERNATIONAL CRIMINAL COURT (17/08/2017) Caso Al Mahdi. El fiscal contra Ahmad Al Faqi Al Mahdi. ICC-01/1201/15. Reparación <https://www.icc-cpi.int/mali/al-mahdi> [Consulta: 06/12/2017]

- JHA, U. C.; RATNABALI, K. (2017) The Law of Armed Conflict: An Introduction. Delhi: Vjj Books India Pvt Ltd., 2017

- TURKU, H. (2017) The Destruction of Cultural Property as a Weapon of War. Basingstoke, Reino Unido: Palgrave Macmillan, 2017 